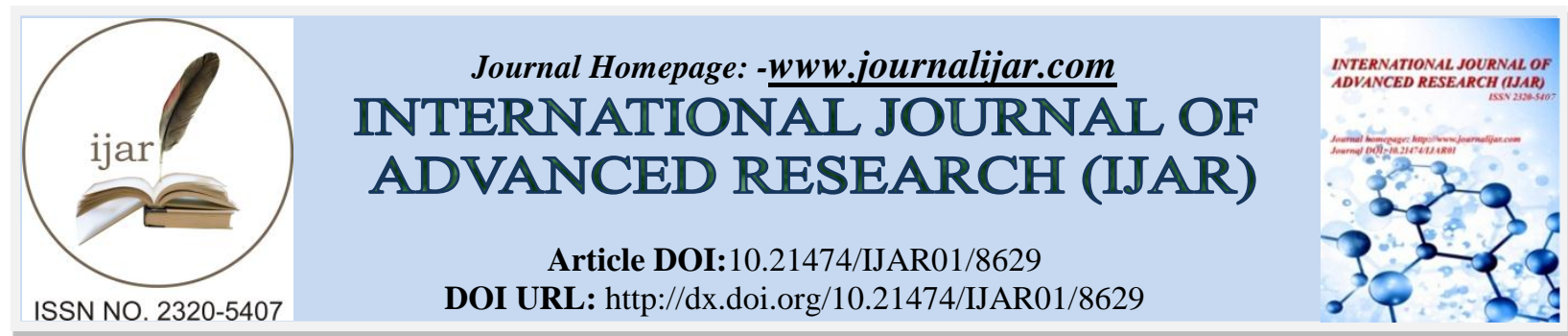

RESEARCH ARTICLE

\title{
FROM ARTIFICIAL INTELLIGENCE TO ARTIFICIAL CONSCIOUSNESS: POSSIBLE LEGAL BASES FOR THE HUMAN-ROBOT RELATIONSHIPS IN THE FUTURE.
}

1. Dsc. Ph.D., Associate Professor; Technical University, Rzeszow, Poland.

2. Ph.D., Assistant Professor Istanbul Commerce University, Istanbul, Turkey.

\section{Manuscript Info}

Manuscript History

Received: 06 January 2018

Published: March 2019

Key words:-

Artificial Intelligence, Digital Economy,

Copyright Law, Cybersecurity

Challenges.
Final Accepted: 08 February 2019

\begin{abstract}
In the future, robots will increasingly resemble human beings and people will engage in social interaction with them. Accordingly, this paper aims to pave the way for analyse the research problem in the case of social robots, the probable legal status of artificial intelligence in the future. The article will discuss the differences between artificial intelligence versus artificial consciousness because AI poses societal challenges so it is currently undergoing a number of important developments and the law must be rapidly changed in society so that firstly, the difference between artificial intelligence and artificial consciousness is attempted to be demystified. Subsequently, the analysis will be subjected to a current legal status of Artificial Intelligence in EU with particular emphasis on case-law in matters of intellectual property. Also possible future scenarios will be discussed in this article The starting point of the research were source queries and literature studies aimed at jointly defining competence profiles of robot-human and key from the point of view of cybersecurity challenges 4.0. Next, the most important legal and political EU programming documents were analysed and assessed in terms of their vision of society 4.0. Next, a decision-making method was used to see the impact of particular instruments applied by the union in the framework of the policy of cyberspace protection and the phenomenon of robot-human relations. In connection with this, the following basic questions arise: firstly, the direction in which contemporary policy of combating cyber-terrorism should be aimed at institutional and legal matters, and secondly, to what extent well-guided cyber-security policy is able to influence the security of relations robot-human?
\end{abstract}

Copy Right, IJAR, 2019,. All rights reserved.

\section{Introduction}

According to some scholars, until the mid of this century, artificial intelligence was beyond human understanding and control (Barfield, 2015). If this happens, humanity will encounter unprecedented legal problems. To complicate matters further, the anthropocentric standpoint of today's legal systems does not allow humanity to address these problems (Pagallo, 2013). This anthropocentric approach views our species at the center of the universe (Leach, 2015). Yet, in line with the prediction put forth by Ray Kurzweil, artificial intelligence will be a billion times more 
capable than human intelligence until the mid of this century (Hansell \& Grassie, 2011). If this happens, the earth will embark on a new era in biological evolution. Today, humanity is about to create new inorganic species which will probably dominate the world. These more intelligent life forms may one day demand the same rights as those of humans. This will inevitably lead to the emergence of complex legal problems for humanity (Barfield, 2015). Therefore, it may be stated that the future legal status of artificial intelligence is quite uncertain (Ersoy, 2017). In current view, robots are regarded as a property; nevertheless, in some countries, a body of research regarding the rights of the robots has been conducted (Turkle, 2011). In this regard, there are different approaches. Some researchers suggested that future conscious robots can be regarded in the same category and status as slaves in the ancient times (Kakoudaki, 2014). According to this view, the rules of ancient Roman law on slavery are proposed as a legal framework to grant robots a legal accountability (Pagallo, 2013). Implementing slave laws to robots is an anthropocentric approach; however, treating a smarter and superior creature as a slave would not be a sustainable behavior for humanity. In the long-run, it can be said that equality based solutions will prove to be more reasonable, and it would be an existential problem for humanity to put future human-robot relations on a proper legal basis. This paper, therefore, aims to pave the way for the probable legal status of artificial intelligence in the future.

\section{Artificial Intelligence versus Artificial Consciousness}

Intelligence refers to an agent that perceives its environment and regulates behaviors according to environmental conditions (Dieter Schmalstieg \& Hollerer, 2016). It is the ability to learn new information and understand the causes that reveal new situations (Rhem, 2005). Intelligence ability is a compilation of brain-based cognitive abilities such as comprehending ideas, making plans, reasoning, solving problems, cogitating abstractly and learning from experience (Goldstein, Princiotta, \& Naglieri, 2014). The inter-correlations among these brain-based abilities reflect the degree of IQ (Miller, 2009). Intelligence and consciousness are inter-related concepts; thus, they cannot be separated from each other. Plus, there is no single definition of consciousness generally adopted by all. Therefore, it is difficult to provide a clear and concise definition. While bringing up consciousness, scientists often do not make a strict definition that separates consciousness from other concepts related to mind (Izard, 1991). In view of the anthropocentric approaches, consciousness is regarded as a concept that belongs to humans merely. Nonetheless, some animals may be conscious in some sense. This issue remains to be contradictory since, in the case of animals, it is often difficult to identify a unique behavior resulting from consciousness (Shettleworth, 2010). Moreover, learning and reasoning activities can be regarded as a form of primitive consciousness, and the evolution of consciousness is associated with activities that have to do with learning and reasoning (Jaynes, 1976). Therefore, it can be said that the studies on machine learning have paved the way for the consciousness of machines. General artificial intelligence (AGI) is far from attaining consciousness but studies on machine learning have come a long way (Fandango, 2017). Some scholars suggest that consciousness is a mysterious concept (Hancock, 2015); and is related to reality (Wilber, 2002). In addition, it is viewed as a fundamental component of reality (Bogdashina, 2013). Consciousness associated with questioning the reality is similar to the thoughts of Rene Descartes who questioned everything including his own existence (Sartre, 2002). While some definitions also emphasize that reality and existence may be associated with religion, other definitions reflect a mechanistic view.

Artificial Intelligence is a branch of computer science that focuses on reasoning, perception and learning capabilities of computers (Bar-Cohen, Hanson, \& Marom, 2009). Machines that have the skills of humans have always been imagined throughout history. Autonomous tools were firstly mentioned in The Iliad of Homer as tripods of the god Hephaestus. The Greek philosopher and scientist Aristotle also imagined autonomous tools (Nilsson, 2010). Thomas Hobbes is another name who mentioned in his book Leviathan that producing an artificial animal could be possible (Hobbes, 1651). It is seen that modern artificial intelligence studies are a reflection of these historic imaginations. The veiled drive that lies behind this may be to create an artificially conscious creature like Pinocchio (Lavender, 2011).

Defined as computer systems that simulate human intelligence using techniques of semantic representation and processing (Levy, 1997), artificial intelligence simply refers to simulating human intelligence in computer based applications (Donelan, Kear, \& Ramage , 2012). Today, artificial intelligence is about to become an integral part of human life, ranging from autonomous vehicles to virtual assistants (Rose, 2016). Due to the exponential increases in computing power, there has been a dramatic progress in the field of artificial intelligence. Various applications based on artificial intelligence are still in use today. Until the middle of this century, the explosion of intelligence is expected to occur in machines; and accordingly, artificial intelligence will probably go beyond human understanding and control (Barfield, 2015). Today, robots are able to perform routine tasks that are part of business processes.(Bello \& Lokhorst, 2011). However, robots will most likely begin to perform exceptional tasks that 
require cognitive skills such as decision-making and judgment in the future. Some scientists even suggest that computers will become conscious and have emotional as well as spiritual experiences in the future (Thierauf, 2002). Yet, some scholars assert that artificial consciousness is technically impossible (Metzinger, 1995). As a widely accepted view, consciousness is a decisive feature so it is not necessary to be a human. Correspondingly, the views that robots cannot be regarded as legal persons are based on the argument that artificial consciousness can never be made (Pagallo, 2013). According to some scientists, consciousness is an electro-neuro-chemical representation of animal-environment relationships (Henriques, 2011). This neurocognitive approach concordantly asserts that computers imitating biologic intelligence will be consciousness. If brain is regarded as a machine, it is necessary to admit that machines will inevitably gain consciousness; and they will be superior to humans (Kurzweil, 2005).

Furthermore, it can be posited that humanity has recently come to an important turning point in its biological evolution (Soraker \& Steinhart, 2013); and it is possible for the inorganic substance to evolve by passing the same process with carbon molecules (Mintzberg, Ahlstrand, \& Lampel , 2013). Probably artificial intelligence will do this by producing itself in different forms. Hence, humanity will probably live in symbiosis with these new inorganic life forms (Soraker \& Steinhart, 2013).

On the other hand, it is a well-accepted view that people do not always make rational decisions or act rationally. Some researchers even claim that normal human behavior is not rational (Sanderson \& Gruen, 2006) and also some states of human consciousness are considered insane. This view also sparks a serious debate on machine consciousness.

After gaining consciousness, if machines make non-rational decisions, then who is supposed to take on the legal responsibility of these decisions? Robots may also inflict physical or emotional harm to other living creatures (Müller, 2016), which is another aspect of all these relevant debates, and accordingly, it is necessary that all such issues be evaluated from a legal perspective.

\section{Current Legal Status of Artificial Intelligence}

The author of artificial intelligence as notion is J. McCarthy who coined it in 1956 (Rajaraman,2014). The basic issue that needs to be answered is whether the products of artificial intelligence should be protected under copyright law or any related rights. The former grants the protection of strictly creative activities that brings about the creation of a work - a qualified form of human communication. Granting this is an indication of the legislator's concern for the safeguarding of the creator's existence and also generating an incentive for further creative activities. The related law would, in turn, secure the economic effort made to create the conditions for "creation." It is directed not so much toward the creator and the act of creation as long as the conditions justify the creation of the work. Differences are fundamental in this matter (Markiewicz, 2015).

The issue of testing the ability of computer programs to become an author in the understanding of copyright law is not new. However, all attempts to extend qualifications to programs were negated by indicating that the author should put in the work "heart and mind", which definitely lacks in algorithms. The creative activity realized by the computer has been called the so-called computer generated works, which D. Cat describes as "such activity of a computer program, whose result - using general principles of copyright law - cannot be unanimously assigned to the program's creator or a person using this program" (Cat, 1999). This concept, therefore, has to include this kind of a creative activity that comes from the computer itself. In international literature, many attempts have been made to assign authorship to such computer works, which includes the following: 1) programmer creating a computergenerating program, 2) user of the program, 3) programmer and user together, 4) computer program, 5) computer programmer and a programmer in total, 6) a computer program and a user in total, 7) to anyone (Glasser, 2001).

It is accepted broadly that the author of a computer program cannot be ruled out in advance if the algorithm created by him / her created acts of creativity by himself or herself, and the user did not make the creative contribution regarding the creation of the work (Barta, Markiewicz, 1993; Matusiak, 2013). One party should be in favor of its legitimacy; otherwise, this work would entirely be excluded from the scope of implementing copyright law.

There are two ways in which copyright law can address works in which human interaction is minimal or nonexistent. It can either deny copyright protection for works that have been generated by a computer or it can attribute authorship of such works to the creator of the program. 
In the light of art. 1 of Directive 91/250 (O.J.L 122 17.5.1991, p. 42-46) a computer program must fulfill such conditions as a literary work so as to be subject to copyright. However, they were subject to modifications due to the specificity that is characteristic of computer programs. Article 1, paragraph 3 of Directive 91/250 / EEC does not provide any criteria other than originality. All original programs are protected, irrespective of their aesthetic aspects, utility or economic value. The type (regardless of whether it is an operating system, application, or a computer game) and the purpose of the program (educational, entertainment, or utility), its level of complexity or market value have no significance. In addition, they do not have to be completed or to perform their function. Pursuant to art. 1 of Directive 91/250/EEC, Member States shall protect computer programs with copyright as literary works within the scope of the Berne Convention, no matter what form they may take.

The first controversy that is already seen here was signaled previously. It is related to the existence of program generators (with the help of which computer programs can be created) or other software development tools. In connection with this, there appeared in the doctrine proposals the exclusion of the so-called copyright protection from the protection of copyright computer generated works (Radoniewicz, 2009). The Court of Justice of the European Union (CJEU) has also declared on various occasions, particularly in its landmark Infopaq decision (C5/08 Infopaq International A/S v Danske Dagbaldes Forening), that copyright is valid only for original works, and originality needs to reflect the "the intellectual creation of the author". This usually comes to mean that an original work needs to reflect the personality of the author which in other words refers to the fact that a human author is required for a copyright work to exist (Stuglik, 2002).

Various materials, devices as well as tools can be utilized during the process of creating a song. A computer program can also be a tool, and songs can be created by using a properly programmed computer. The development of information technologies, including those that ensure the interactions of computer software users, has brought about a discussion regarding the authorship of the so-called computer-generated works, as reflected in some copyright systems (e.g. in British law) (Guadamuz, 2017). Additionally, section 178 of the Copyright, Designs and Patents Act (CDPA) defines a computer-generated work as one that "is generated by computer in circumstances such that there is no human author of the work". The idea behind such a provision is to generate an exception to all human authorship requirements by recognizing the work that goes into creating a program capable of generating works, even if the creative spur is assumed by the machine. Some case law seems to indicate that this question could be resolved on a case-by-case basis. In the English case of Nova Productions v Mazooma Games [2007], the Court of Appeal needed to make a decision on the authorship of a computer game, and declared that a player's input "is not artistic in nature and he has contributed no skill or labor of an artistic kind". Thus, considering user action based on a case by case standpoint could be viewed as one of the probable solutions to address the problem. Here, the computer program is treated as a tool that ensures further development of a human, and what is at stake here is the indirect human authorship.

It should be noted that there exist no grounds to treat such a situation in the category of co-creativity. Accordingly, software developers assign the status of a co-creator for a work that has been created by means of this tool. Additionally, the very term "compositions generated by a computer" needs to be used with great caution since the song can only be discussed in relation to the results pertaining to human creativity. Therefore, if the result obtained through using a computer did not involve the work of the person who is using it, then - not being a manifestation of creative activity - it is not a work. However, it cannot be ruled out that the development of the so-called artificial intelligence or the use of biological computers using DNA or RNA molecules will force the need to revisit the views regarding the essence of creativity, which would necessitate the breaking of the principle that creative intellectual activity is a right solely for the human being (Nowicka, 2003).

Pursuant to Article 1 Directive 96/9/EC of the European Parliament and of the Council (OJ L.1996.77.20), protection that has been granted to databases does not include computer programs which are used to create or use databases. However, the aforementioned provisions do not allow to separate, as separate objects of protection, databases or computer programs. Thus, it is likely that difficulties arise in a situation in which the database has the features of a work protected by copyright. As article 3 shows that the databases with features of works are covered by copyright, provided that the arrangement or composition must be creative in nature, without prejudice to the rights to use the works (even if it contains unprotected by the law materials. Legal copyright protection of databases refers to the "selection, arrangement or specification" of materials contained in the database. Despite the doubts as to the scope of protection of some computer programs constituting a "skeleton" for electronic databases and describing the structure of such a database, Z. Okon believes that the database and computer program will always be 
independent security objects, and their legal protection should always be justified by security ranks. (Okon, 2015; Filipowicz, 2015).

As is evident from the recital 41 of the preamble to Directive 96/9/EC (OJL 77, 27.3.1996), the purpose of introducing the sui generis right is to provide the database maker with the means to prevent illegal downloading or re-use regarding the entire or substantial part of the database. A separate database protection system generates a new absolute subjective right, which guarantees the exclusive extraction of data contained in the database and their reuse, and at the same time ensures the opposition to certain activities for people who are making use of the databases. The consequence of the introduction of sui generis database protection regulations has resulted in a situation where there is complimentarily in the European Union for the protection of databases in the field of copyright and at the same time sui generis (Bostrom, 2014 ), which means that the sui generis right applies regardless of whether a particular database is protected by basis Directive 2001/29/EC of the European Parliament and the Council dated May22, 2001 (O.J.L. 167, 22.6.2001)regarding the harmonization of certain provisions on copyright and related rights in the information society) aimed at the harmonization of internal legislation in the area of copyright and related rights. Its main task was to take copyrights under protection and contribute to the decline in piracy. It is known that digital technology brings about new risks concerning the exploitation of works, and at the same time, facilitates the infringements of copyright. For this reason, the directive, which recognizes and regulates the impact of new technologies on copyright, confirms the strengthening of the legislative direction initiated by the adoption of the Copyright Treaty (WCT) and the Treaty on Artistic Works and Phonograms (WPPT).

By means of a legal instrument, namely a directive, the goal is to create a certain flexible general legal framework for the European Union area to support and also facilitate the development of information society. We can now observe the subsequent efforts of the European Union to strengthen the internal market through new products and services. The construction of legal safeguards in this sector increases, undoubtedly, from the investments of entrepreneurs in terms of creativity and innovation, including the network infrastructure as well. In total, the protection of copyright is necessary in relation to the interests of not only the creators, contractors, producers or entrepreneurs in general, operating in this sector of European industry, but also of culture and the broadly understood group of recipients benefiting from others' creative activities. Undoubtedly, everyone in this sector is aware of the risks that digital technology entails with regard to copyright, in particular the Internet (the most perfect copying machine that exists in the world).

Directive 2001/29 precisely defined the area which copyright and related rights apply to in single market, with particular emphasis on the information society. However, it does not apply to all copyrights and related rights so it refers to specific entities (creators, performers, producers of phonograms, films and broadcasting organizations) as well as to specific fields of exploitation. It should be noted that Directive 2001/29 does not regulate either personal rights or other rights, such as droit de suite. Directive 2001/29 on copyright applies to issues related to restrictions and exceptions concerning the exercise of rights, viewed from an overall perspective (use via the Internet and elsewhere). It also aims to achieve a relative balance between the public interest, i.e. access to culture in the first place, by guaranteeing the free exercise of rights, and the interest of the copyright owner, i.e. receiving compensation for economic losses caused by such a use.

There has been no holistic approach put forth so far that unifies the fundamental issue for copyright, which could solve the growing problems of non-adjustment of the legal regulations to modern technologies. The draft directive of the European Parliament and of the Council on copyright in digital single market (COM /2016/593/FINAL) offers a general impression of the compilation of various issues within a single act; they are sometimes presented quite chaotically and not fully consistent with the earlier copyright directives. Many amendments that have been proposed during the legislative process do not facilitate the interpretation of the entire project at all either. The aforementioned study can be summarized with the conclusion that despite the obvious need to regulate the problems of copyright in the digital single market, it is required to analyze each of them thoroughly and separately to discuss and think about how to solve them.

Directive 2009/24/EC (O.J. L.111, 5.5.2009) of the European Parliament and the Council on the legal protection of computer programs for a computer program recognizes a program in any form, including a program integrated with computer hardware. This act covers the conceptual scope in pt. 7 also preparatory design work that leads to the development of a computer program with the reservation, however, that the nature of the preparatory work is in such a form that a computer program can use it at a later stage. Directive 2009/24/EC granted computer programs the 
same copyright protection as is accorded to literary works within the scope of the Berne Convention. Protection is granted if the computer program possesses the characteristics of originality, in the sense that it is the creation of the author himself or herself. Accordingly, authors are authorized to be the creator of the computer program, and if the program was created by several people, i.e. we have co-authorship with the co-authorship (unless the program was created as part of performing official duties, then the copyright belongs to the employer).The problem may be the question of defining the boundary between protected and unprotected elements of computer programs. Copyright protection will not be limited only to literal elements, i.e. source code and object code, but it will also contain other elements characterized by the artist's expression. Protection, in turn, does not apply to "extra-text" elements such as algorithm, program structure, programming language or functions.

That there was a problem of an absence of protection for computer generated works is recognized in the expanded embrace of copyright to these works. However, should we understand the computer generated works and what the copyright expansion mean in this case? The original understanding is in part recognized by Clark and Smyth, (Clark \& Smyth, 1997) when they refer to the expansion of "recognition that a computer-generated work may attract copyright will be of considerable importance to the artistic community."(Lambert, 2017).

The philosophy is concerned to some extent with an artistic (and literary) aspect of appreciation in mind. As J. Grimmelmann also notes, "copyright's ideal of romantic readership involves humans writing for other humans." (Grimmelmann, 2016). Even with the copyright for (certain) computer generated works in mind, there is still an artistic and artistic community - if commercially artistic - notion at play.

However, new technological events and modern examples of computer generated works are much more advanced than the ones when the original expansion occurred so in May 2016 when the European Parliament prepared recommendations on robotics (2016/2145(INI)), demanding that the European Commission adjust the criterion of 'the author's own intellectual creation' in relation to works created by robots or computers. The need for such a requirement - for example due to the growing economic importance of automatically generated works - is put forth by Madeleine de Cock Buning from Utrecht University who is dealing with the implementation of artificial intelligence and other discriminatory technologies in legal system (Buning\&Bruin, 2017).

The impact of Artificial Intelligence (AI) has a cross-border nature; therefore, supra-national policy frameworks will also need to be established. The EESC recommends that the EU take the lead globally in establishing clear global policy frameworks for AI in line with fundamental rights and European values. The EESC is able and willing to make a contribution to this matter. The EESC currently identifies 11 areas where AI poses societal challenges. These areas are listed as ethics, safety, privacy, transparency and accountability, work, education and skills, (in)equality and inclusiveness, law and regulations, governance and democracy, warfare, and finally superintelligence. The EESC makes the following recommendations (OJ C 13, 15.1.2016, p. 161.).

AI is currently undergoing a number of important developments and rapidly being applied in society. The AI market amounts to around USD 664 million and is expected to grow to USD 38,8 billion by 2025. As AI can have both positive and negative impact on the society at large, the EESC has assumed the mission of monitoring developments surrounding AI closely. They perform the monitoring not only from a technical perspective but also specifically from an ethical, safety and societal perspective (2017/C 288/01).

A few extensions to the current copyright laws were enacted to deal with the issue. Regulation (EU) 2016/679 and 2018/1807 of the European Parliament and the Council dated 14 November 2018 (OJL 303, 14.11.2018) worked on a framework for the free flow of non-personal data in the European Union. For example, regulation $2016 / 679$ stipulates that Member States may not restrict or prohibit the free flow of personal data within the Union for reasons related to the protection of individuals with regard to the processing of personal and non-personal data. The Regulation establishes the same principle of free movement in the Union concerning non-personal data, except where a restriction or prohibition is justified on grounds of public security. Regulation (EU) 2016/679 and Regulation 2018/1807 comprise a coherent set of rules as regards the free flow of different types of data. Furthermore, Regulation 2018/1807 applies to the broadly understood data processing, involving the use of all types of information systems, irrespective of whether they are located in the user's premises or are outsourced to a service provider. Pursuant to art. 2 of the Regulation, this will apply to the storage or other processing of electronic data, other than personal data, e.g. IT algorithms, data generated by machines, data from sensors in traffic lights for more efficient traffic management or optimization of routes throughout the entire territory European Union. As a 
consequence, this regulation will apply to all the entities which store or process non-personal data as long as they perform these activities within the EU. The European Union is trying to approach the issue of non-personal data flow as broadly as possible, giving - as it seems - a green light for the relatively unrestrained development of the market, e.g. Big Data, IoT (Internet of Things) or artificial intelligence (AI). The Regulation applies to all types of information systems, regardless of whether they are located in the user's premises or are outsourced to a storage service provider or other type of data processing. Additionally, different types of cloud computing should be covered by the Regulation.

\section{Future Possibilities}

The market with robots that are capable of interacting with people is growing every year, which results from the fact that the new machine functions are quickly refined. They can be successfully used as accompanying devices or in different areas including rehabilitation or educational processes. It should be noted that although the integration of the world of people and machines is not a new phenomenon, there may be some uncertainties related to the extent of the interference of advanced technology in personal and even intimate human life (Mamak, 2017). Both the world of science and science-fiction literature agrees on a scenario in which robots will become closer to humans than they have ever been before. Intimate contacts and emotional engagement in the relationship with the machine, which is likely to resemble that with a human being, today already, incite ethicists and lawyers to deal with questions about the human-robot relationship in the future. It should also be added that within social robotics, one is able to make a certain distinction owing to the corporeality of the machines (anthropomorphic and zoomorphic), which is significant for them as perceived by potential users. "The valley of the amazing" should also be taken into account as an integral element, which can provide many indications about the trials and consequences of establishing artificial companions (Wójtowicz, 2015).

Many scholars' suggestions that refer to the ordering of the characteristic features of robots, particularly those called social, allow to distinguish several groups of them. These are including the following features: form, shape, advanced level of interactive functions, autonomy of action, the ability to learn independently, that is, increasing the functionality, imitating emotions, having "mental states", displaying personality traits, and one of the most important properties - multitasking. It can be the line between an ordinary automated device designed to perform a small number of tasks and machines that - like a human being - are able to adapt to new situations. It would be apt to mention that in the 18th and 21st century "devices imitating" living organisms, especially humans, enjoyed unflagging popularity. It might seem that a "social robot" should be a machine that most often resembles a human being that can perform certain activities and have functions that allow interaction with the environment (Darling, 2012). Such a narrowing down, on the other hand, because those robots of anthropomorphic shape would be excluded although they meet the other relevant criteria. Hence, in an attempt to construct a definition of social robots, a certain gradation of device types should be made owing to anthropomorphic, zoomorphic or other embodiments (Acemoglu\&Restrepo, 2018). Another issue is the multitude of terms used to describe the same type of machines. In the literature on the subject, you can see the functioning of such concepts as "robot", "android", "automaton", "relational artifact", and "simulator" (Sarowski, 2017).

It is interesting to analyze the research problem in the case of social robots, in which the anthropomorphic form of the machine, its behavior, imitation of emotional states and possession of some sort of personality are exposed for destruction (Turing, 2018). Both the issue of emotions and personality play a key role in the description of machines that are currently called social robots. This aspect is emphasized particularly in various studies concerned with the possibilities of further development of such devices. Christoph Bartneck and Jodi Forlizzi (Bartneck\&Forlizzi, 2004) proposed five machine-specific properties required enable them to acquire social competences. Among them, the most important is the issue of the anthropomorphic embodiment of artificial intelligence, i.e. the shape of the robot, the material it is made of, and its behavior. The modality, which authors understand as the number of communication channels (e.g. visual, tactile, auditory or gestural) is also a significant aspect. Another important element is the adaptation of social norms that condition interaction, the manifestation of autonomous action (at least to a certain extent) and interactivity. On the basis of theirs, a proposal for a definition was proposed according to which the social robot is "an autonomous or semi-autonomous robot that communicates and interacts with humans, following social norms expected by people to whom this robot is designed. 


\section{Conclusions:-}

The analysis of normative foundations allowed to show the dependence of the cyberspace protection policy on the level of Member States' integration, and in particular on new threats and cybersecurity challenges (social and civilization changes accompanying from web 2.0 to Society 4.0 ) although the process is relatively slow.

Robotic technologies are advancing in various areas of everyday life, ranging from businesses to private homes; from logistics to crowd controlling and warfare. On the other hand, the development of robotic technologies causes several social and ethical problems. For instance, relation between users and socially interactive robots may lead to psychological dependencies which are likely to be exploited by the companies creating these robots. Research on ethics and rights of robots in different cultural environments is also essential since similar problems in different cultures may bring about different results (Scheutz 2012; Malle, Scheutz, Arnold, Voiklis, Cusimano ,2015).

Nick Bostrom indicates that the level of artificial intelligence is systematically increasing and heading towards a direction that is even beyond the human level. It is currently at a much lower level, but in a few years' time, it can attain the level of a cat or a dog (Bostrom, 2014). Thus, the development of artificial intelligence allows to overcome a certain level that will be closer to the intelligence of a dog than that of a hamster, and in this form it will be implemented for robots. Based on this assumption, it will be possible to punish robots (in colloquial terms - what applies to dogs). However, the further development of artificial intelligence may even result in the application of criminal laws to robots.

Robots will resemble human beings all the time more in the future; and people will engage in social interactions with robots. As such, the need to address the legal, social and ethical issues will become progressively more important. People will perceive robots as social actors in their physical environment. Therefore, they will be expected to display ethical behavior towards robots. For future generations, interaction with robots will be an ordinary daily activity. Before the robots will take their place in the society, the relevant legal gaps need to be bridged and create appropriate legal instruments in this areaawareness for social and ethical issues are to be raised.

At the moment, the British law model of assigning copyright to a creator of artificial intelligence is the most appropriate. This approach ensures that companies continue to invest in technology and get a return on their ventures. However, an important question is whether robots should be given human status and rights. Although this problem has not yet been solved, it remains undoubtedly on the agenda, and its result is not synonymous with replanting at the moment.

\section{References:-}

1. Acemoglu, D., Restrepo, P. (2018), Artificial Intelligence, Automation and Work, NBER Working Paper 24196.

2. Bar-Cohen, Y., Hanson, D., \&Marom, A. (2009). The Coming Robot Revolution: Expectations and Fears About Emerging Intelligent, Humanlike Machines. New York: Springer.

3. Barta J., Markiewicz R. (1993), The main problems of computer law.

4. Barfield, W. (2015). Cyber-Humans: Our Future with Machines .Chaphel Hill: Springer.

5. Bartneck Ch., Forlizzi J. (2004), A Design-Centred Framework for Social HumanRobot Interaction.

6. Bello, P., \&Lokhorst, G.-J.(2011). Current Trends i Robotics. P. Lin, K. Abney, G.

7. Bogdashina, O. (2013). Autism and Spirituality: Psyche, Self and Spirit in People on the Autism Spectrum. London: Jessica Kingsley Publishers.

8. Bostrom P. (2014), Superintelligence: Paths, Dangers, Strategies.

9. Buning, de Cock M, Briun R. (2017), Autonomous intelligent cars: proof that the EPSRC Principles are futureproof.

10. Cat D. (1999), [in:] Barta J., Markiewicz R. Copyright law and technical progress.

11. CJEU Order C-5/08 Infopaq International A/S v Danske DagbaldesForening

12. Clark, Smyth (1997), Intellectual Property Law in Ireland Dublin.

13. Dieter Schmalstieg, \&Hollerer, T. (2016). Augmented Reality: Principles and Practice. New York: Pearson Education.

14. Darling K. (2012), Extending Legal Rights to Social Robots.

15. Donelan, H., Kear, K., \&Ramage , M. (2012). Online Communication and Collaboration: A Reader . New York: Taylor \& Francis. 
16. Ersoy, Ç. (2017). Robotlar, YapayZekaveHukuk. İstanbul: On İkiLevha.

17. Fandango, A. (2017). Python Data Analysis . Birmingham: Packt Publishing.

18. Filipowicz T. (2015).,Zasadarównegotraktowaniawykonawców

W zamówieniachpublicznychdotyczącychtechnologiiinformatycznych.

19. Goldstein, S., Princiotta, D., \&Naglieri, J. A. (2014). Handbook of Intelligence: Evolutionary Theory, Historical Perspective, and Current Concepts. New York: Springer.

20. Graaf M. (2016), An Ethical Evaluation of Human-Robot Relationships, Int J of SocRobotics .

21. Glasser D (2001)., Copyrights in Computer-Generated Works: Whom, If Anyone, do We Reward?.

22. Grimmelmann J. (2016), Copyright for Literate Robots.

23. Guadamuz A. (2017), Artificial intelligence and copyright https://www.wipo.int/wipo_magazine/en/2017/05/article_0003.html

24. Hancock, G. (2015). The Divine Spark: Psychedelics, Consciousness and the Birth of Civilization .Carsbad: Hay House.

25. Hansell, G. R., \&Grassie, W. (2011). H+/-: Transhumanism and Its Critics. Philadelphia: Metanexus Institute.

26. Henriques, G. (2011). A New Unified Theory of Psychology . New York: Springer.

27. Hobbes, T. (1651).Leviathan . Overland Park: Digireads.com Publishing .

28. Izard, C. E. (1991). The Psychology of Emotions. New York: Springer.

29. Jaynes, J. (1976). The Origin of the Consciousness in the Breakdown of the Bicameral Mind . New York: Mariner Books.

30. Kakoudaki, D. (2014). Anatomy of a Robot: Literature, Cinema, and the Cultural Work of Artificial . New Brunswick: Rutgers University Press.

31. Kurzweil, R. (2005). The Singularity is Near. London: Viking Penguin.

32. Lambert P. (2017), Computer Generated Works and Copyright: Selfies, Traps, Robots, AI and Machine Learning.

33. Lavender, I. (2011). Race in American Science Fiction . Bloomington: Indiana University Press.

34. Leach, R. (2015). Political Ideology in Britain . London: Palgrave Macmillan.

35. Levy, M. (1997). Computer-Assisted Language Learning: Context and Conceptualization . New York: Oxford University Press.

36. Malle B.F., Scheutz M., Arnold T., Voiklis J., Cusimano C. (2015) Sacrifice one for the good of many? People apply different moral norms to human agents, Porland.

37. Mamak K. (2017), Prawo karne przyszłości, Wolter Kluwer, Warsaw.

38. Markiewicz R. (2015), Playing with copyright.

39. Matusiak A. (2013), Computer game.

40. Metzinger, T. (1995).Conscious Experience. Lawrence: Imprint Academic Schöningh.

41. Miller, J. M. (2009). 21st Century Criminology: A Reference Handbook. Thousand Oaks: SAGE.

42. Mintzberg, H., Ahlstrand, B., \&Lampel , J. (2013). Strategy Bites Back: It is far more, then you imagined. Harlow: Prentice Hall.

43. Müller, V. C. (2016). Fundamental Issues of Artificial Intelligence . New York: Springer.

44. Nilsson, N. J. (2010). The Quest for Artificial Intelligence. New York: Chambridge University Press.

45. Nowicka A. (2003), [in:] J. Barta (ed.), System prawaprywatnego, t. 13, Prawoautorskie.

46. Okon Z. (2015) [in:] Flisak D (ed.), Prawoautorskieiprawapokrewne. Komentarz.

47. Radoniewicz F. (2009), Ochronaprogramówkomputerowych w prawie UE (cz. I).

48. Rajaraman V. (2014), John McCarthy - Father of Artificial Intelligence.

49. Pagallo, U. (2013). The Laws of Robots: Crimes, Contracts, and Torts . New York: Springer.

50. Rhem, A. J. (2005). UML for Developing Knowledge Management Systems . Boca Raton: CRC Press.

51. Rose, G. (2016). The Fourth Industrial Revolution: A Davos Reader . Davos: Council on Foreign Relations.

52. Sanderson, C., \&Gruen, R. (2006).Analytical Models for Decision-Making. Berkshire: McGraw-Hill.

53. Sartre, J.-P. (2002). Sketch for a Theory of the Emotions . London: Routledge.

54. Sarowski Ł. (2017), Robot społeczny — wprowadzenie do zagadnienia, rocznikikulturoznawcze.

55. Scheutz M. (2012) The inherent dangers of unidirectional emotional bonds between humans and socially interactive robots [in:] Lin P., Abney K., Bekey G.A. (eds.) Robot ethics: the ethical and social implications of robotics.

56. Shettleworth, S. J. (2010). Cognition, Evolution, and Behavior . Oxford: Oxford University Press.

57. Soraker, J. H., \& Steinhart, E. (2013). Singularity Hypotheses: A Scientific and Philosophical Assessment. London: Springer. 
58. Stuglik A. (2002), Program komputerowyainneutwory z zakresuinformatyki. the English case of Nova Productions v Mazooma Games [2007].

59. Thierauf, R. J. (2002). Effective Business Intelligence Systems. Westport: Oxford University Press.

60. Turkle, S. (2011). Alone Together: Why We Expect More from Technology and Less from Each Other . New York: RHYW.

61. Turing A. (2018), Computing Machinery and Intelligence, http://phil415.pbworks.com/f/TuringComputing.pdf

62. Wilber, K. (2002). The Spectrum of Consciousness . Delhi: Theosophical Publishing House.

63. Wójtowicz E. (2015), W stronędolinyniesamowitości [in:] Zawojski P. (ed.) Bio-techno-logicznyświat: bioartorazsztukatechnonaukowa w czasachposthumanizmuitranshumanizmu.

64. Papers must be sent in electronic format (DOC) to the editorial board at the following address: submission_paper@amp.ase.ro, using the following form for. 